Canadian

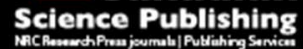

Canadian Journal of Microbiology Revue canadienne de de microbiologie

\title{
Antimicrobial use in swine production and its effect on the swine gut microbiota and antimicrobial resistance.
}

\begin{tabular}{|r|l|}
\hline Journal: & Canadian Journal of Microbiology \\
\hline Manuscript ID & cjm-2015-0239.R2 \\
\hline Manuscript Type: & Mini-Review \\
\hline Date Submitted by the Author: & 13 -Aug-2015 \\
\hline Complete List of Authors: & $\begin{array}{l}\text { Holman, Devin; McGill, Animal Science } \\
\text { Chenier, Martin; McGill University, Food Science, Animal Science }\end{array}$ \\
\hline Keyword: & $\begin{array}{l}\text { swine production, antimicrobials, gut microbiota, phylogenetic biodiversity, } \\
\text { antimicrobial resistance }\end{array}$ \\
\hline
\end{tabular}

\section{SCHOLARONE \\ Manuscripts}


1 Antimicrobial use in swine production and its effect on the swine gut microbiota and 2 antimicrobial resistance

4 Devin B. Holman ${ }^{\mathrm{a}, \#}$, Martin R. Chénier, ${ }^{\mathrm{a}, \mathrm{b}, *}$

7 a Department of Animal Science, ${ }^{\mathrm{b}}$ Department of Food Science and Agricultural Chemistry, 8 McGill University, Ste-Anne-de-Bellevue, Quebec, Canada, H9X 3V9.

$11 *$ Corresponding author: Mailing address: Department of Food Science and Agricultural

12 Chemistry, Faculty of Agricultural and Environmental Sciences, McGill University, 21,111

13 Lakeshore Road, Ste-Anne-de-Bellevue, QC, Canada, H9X 3V9. Phone: (+1) 514-398-7923.

14 Fax: (+1) 514-398-7977. Email: martin.chenier@mcgill.ca.

15

16 \#: Present Address: Lethbridge Research Centre, Agriculture and Agri-Food Canada

$175403-1^{\text {st }}$ Avenue South, Lethbridge, Alberta, Canada, T1J 4B1.

18 
Abstract

21 Antimicrobials have been used in swine production at subtherapeutic levels since the early 1950s

22 to increase feed efficiency and promote growth. In North America, a number of antimicrobials

23 are available for use in swine. However, the continuous administration of subtherapeutic, low

24 concentrations of antimicrobials to pigs also provides selective pressure for antimicrobial-

25 resistant bacteria and resistance determinants. For this reason, subtherapeutic antimicrobial use

26 in livestock remains a source of controversy and concern. The swine gut microbiota

27 demonstrates a number of changes in response to antimicrobial administration depending on the

28 dosage, duration of treatment, age of the pigs, and gut location that is sampled. Both culture-

29 independent and dependent studies have also shown that the swine gut microbiota contains a

30 large number of antimicrobial resistance determinants even in the absence of antimicrobial

31 exposure. Heavy metals, such as zinc and copper, which are often added at relatively high doses

32 to swine feed, may also play a role in maintaining antimicrobial resistance and on the stability of

33 the swine gut microbiota. This review focuses on the use of antimicrobials in swine production,

34 with an emphasis on the North American regulatory context, and their effect on the swine gut

35 microbiota and on antimicrobial resistance determinants in the gut microbiota.

37 Key Words: swine production, antimicrobials, gut microbiota, phylogenetic biodiversity, 38 antimicrobial resistance 


\section{Introduction}

Pork remains the most widely consumed meat with an estimated 114.5 million tonnes of

43 pork eaten worldwide in 2013 (Food and Agriculture Organization 2014). Globally, swine (Sus

44 scrofa domesticus) production has steadily increased over the past 50 years with a total inventory

45 of 941 million pigs and over 106 million kg of pig meat produced in 2009 (Food and Agriculture

46 Organization 2012), totals higher than those for all other meat sources. Modern swine operations

47 are much larger with increasingly greater numbers of pigs raised per farm (United States

48 Department of Agriculture 2008). Antimicrobials have been used for over 60 years at all stages

49 of swine production (Jukes et al. 1950) and larger swine operations are more likely to use

50 antimicrobials for disease prevention and growth promotion (MacDonald and McBride 2009).

51 The four main reasons for antimicrobial administration are: 1) the treatment of digestive,

52 skin, respiratory, and other infections, 2) as a prophylactic measure to prevent infectious disease

53 at specific stages of swine rearing, for example to prevent diarrhea at weaning, 3) as a

54 metaphylactic treatment to treat large numbers of animals when disease is observed in a

55 proportion of the herd, and 4) as growth promoters to stimulate growth rates and improve feed

56 conversion efficiency (Viola and DeVincent 2006). Antimicrobials administrated for the

57 purpose of growth promotion are given to all animals at subtherapeutic levels while individual or

58 small numbers of pigs (prophylaxis) or the entire herd (metaphylaxis) may be treated with higher

59 levels of antimicrobials (therapeutic) to treat infectious disease (McEwen and Fedorka-Cray

60 2002). Subtherapeutic is defined as a dosage that is lower than what would be required for

61 disease treatment (therapeutic) (Allen et al. 2013). The administration route of antimicrobials is

62 usually via feed, although antimicrobials may also be given through intramuscular injection or in

63 drinking water (Public Health Agency of Canada 2014). 
Worldwide, it is estimated that greater than $50 \%$ of antimicrobials produced are

65 consumed by food-producing animals (World Health Organization 2012). China, the world's

66 biggest swine-producing country (Food and Agriculture Organization 2012), is also the largest

67 consumer of antimicrobials in livestock, with nearly 100 million $\mathrm{kg}$ added to feed each year

68 (Hvistendahl 2012). In the United States, over 50\% of all antimicrobials sold (excluding

69 ionophores) are used in food-producing animals (United States Food and Drug Administration

70 2011) and over $90 \%$ of nursery and grower/finishing pigs receive antimicrobials in their feed at

71 some point (United States Department of Agriculture 2007). In Canada, over 85\% of all

72 antimicrobials sold (excluding ionophores) are used in food-producing animals and 90 to $95 \%$ of

73 pigs are exposed to antimicrobials during production (Deckert et al. 2010). The objective of this

74 review is to summarize the use of antimicrobials in swine production, with an emphasis on the

75 North American industry, and to evaluate the effect these antimicrobials have on the cultivable

76 and uncultivable bacteria in the swine gut microbiota and on antimicrobial resistance

77 determinants in the gut microbiota. The literature search was conducted from January to March

782015 using $\quad$ Google Scholar $\quad$ (scholar.google.ca), $\quad$ PubMed

79 (http://www.ncbi.nlm.nih.gov./entrez/query.fcgi), and Scopus (http://www.scopus.com). Studies

80 that investigated the effect of antimicrobials on the swine gut microbiota and/or on antimicrobial

81 resistance in commensal bacteria were included. Search terms included combinations of:

82 antibiotics OR antimicrobials, swine OR pigs, microbiota OR microbiome, resistance OR

83 resistant, anaerobic bacteria OR commensal bacteria.

\section{Therapeutic use of antimicrobials}

85 Modern animal husbandry often involves having a large number of animals kept in close

86 proximity with one another. As a result, it provides conditions that are optimal for the spread of 
87 infectious disease. These conditions can necessitate the use of antimicrobials to control disease 88 and prevent disease in other animals, i.e. metaphylaxis (Fluit et al. 2006). The duration of 89 antimicrobial disease treatment in swine typically ranges from 20-40 days (Stone et al. 2009).

90 The treatment of individual pigs via intramuscular injection is generally only used in cases of 91 acute, severe infection (Friendship and Prescott 2006). For prophylactic and metaphylactic 92 indications in Canadian swine herds, 10 antimicrobial products may be administered to pigs at 93 concentrations between 13.8 and $400 \mathrm{mg} \mathrm{kg}^{-1}$ feed for either a specific duration (two to six 94 weeks) or for an undefined period of time (generally in weeks; Canadian Food Inspection 95 Agency 2015). For a specific type of illness, pigs can be treated with one of eight antimicrobial 96 agents at concentrations of 27.5 to $500 \mathrm{mg} \mathrm{kg}^{-1}$ feed for a period of five days to seven weeks

97 (Canadian Food Inspection Agency 2015).

98 Subtherapeutic use of antimicrobials

99 Subtherapeutic use of antimicrobials in particular remains a source of controversy since

100 its purpose is usually one that is unrelated to disease treatment and instead focused on the growth

101 performance of the animal. Due to the fact that the subtherapeutic use of antimicrobials usually 102 results in the long-term, continuous exposure of large numbers of pigs to antimicrobials, it plays 103 a larger role in the persistence and dissemination of antimicrobial resistance than therapeutic use, 104 which is much shorter in duration, at higher doses, and usually involves fewer pigs being treated 105 (Marshall and Levy 2011). This effect has been observed in pigs where swine farms using 106 subtherapeutic antimicrobials had higher levels of antimicrobial-resistant Gram-negative fecal 107 bacteria than swine farms where antimicrobials were only used for therapeutic purposes (Gellin 108 et al. 1989). 
110 remains poorly characterized but several potential modes of action have been proposed. These

111 include: 1) reduction of harmful metabolites produced by intestinal bacteria, 2) increased

112 availability of nutrients to the pig that would otherwise be consumed by the gut microbiota, 3)

113 increased absorption of dietary nutrients due to a thinner intestinal wall, and 4) control of

114 endemic subclinical disease (Butaye et al. 2003; Cromwell 2002; Dibner and Richards 2005).

115 This last mechanism, the control of non-specific subclinical disease through antimicrobial 116 administration, is generally the most popular explanation. This is supported by the fact that

117 herds with a higher disease load and those raised in unsanitary conditions respond better to 118 antimicrobials used for growth promotion than do healthy pigs in clean environments (Jin et al. 119 2008; Holman and Chénier 2013). It is notable that antimicrobials also tend to be more 120 efficacious in terms of growth promotion in younger pigs, which are more susceptible to disease, 121 than in older pigs (Bosi et al. 2011; Cromwell 2002). As such, in-feed antimicrobials for the 122 purpose of growth promotion are most effective in the nursery phase with little to no response 123 seen in older pigs (Holt et al. 2011; Skinner et al. 2014). Alternatively, it has also been proposed 124 that antimicrobials have anti-inflammatory effects that are independent of any interaction with 125 the gut microbiota (Niewold 2007).

126 The most commonly used antimicrobials for growth promotion in North American swine 127 operations are tylosin, chlortetracycline, bacitracin, and lincomycin (Deckert et al. 2010; United 128 States Department of Agriculture 2007). The average duration of treatment with these 129 antimicrobials for any purpose in growing-finishing pigs ranges from 22.7 to 76.8 days, with the 130 entire herd being treated at the same time (United States Department of Agriculture 2007). In 131 Canada, nine antimicrobial products may be added to feed at concentrations between 4.4 and 110 
$132 \mathrm{mg}^{-1} \mathrm{~kg}$ feed to improve growth, usually for an undefined duration (weeks to months) during the 133 starting, growing or finishing periods, or during periods of stress (Canadian Food Inspection 134 Agency 2015).

\section{Veterinary and public health concerns}

136 Antimicrobial resistance has been referred to as one of the greatest threats to public 137 health (Marshall and Levy 2011; World Health Organization 2014). Antimicrobial-resistant 138 infections increase morbidity and mortality, as well as the costs associated with treating these 139 infections (Mauldin et al. 2010; Roberts et al. 2009). Meanwhile, the situation is exacerbated by 140 the lack of new antimicrobial drugs in the discovery pipeline and clinical setting (Livermore et 141 al. 2011; Piddock 2012). The use of antimicrobial agents selects for both antimicrobial-resistant 142 bacteria and antimicrobial resistance determinants (Levy and Marshall 2004). In swine 143 production, associations between antimicrobial use and antimicrobial resistance in swine have 144 been well documented (Akwar et al. 2008; Dunlop et al. 1998; Holman and Chénier 2013; Rollo 145 et al. 2010; Rosengren et al. 2007). Resistant bacteria, both pathogenic and commensal, may be 146 passed to humans through food, direct contact with animals, or release of animal waste into the 147 environment (Silbergeld et al. 2008). Importantly, antimicrobial resistance determinants often 148 reside on mobile genetic elements (MGE) such as plasmids, transposons, insertion sequences, 149 integrons, and bacteriophages (reviewed in Frost et al. 2005). These MGEs can be transferred 150 and exchanged among bacteria via horizontal gene transfer processes such as cell-to cell 151 conjugation, bacteriophage-mediated transduction, and transformation (reviewed in Thomas and 152 Nielsen 2005).

153 The threat to human health posed by the agricultural use of antimicrobials has been a 154 source of concern dating back over 45 years when the Swann report in the UK first 
155 recommended that antibiotics added in animal feed should be of no therapeutic value in human 156 medicine (Swann et al. 1969). In swine, resistance to tetracyclines, macrolides, lincosamides, 157 and bacitracin has been observed most frequently, and not surprisingly these antimicrobials are 158 used most often in swine production (Public Health Agency of Canada 2014; Frye et al. 2011). 159 The World Health Organization (2011) has classified macrolides (tylosin), tetracyclines 160 (chlortetracycline), and lincomycin (lincosamides) as highly important or critically important for 161 human medicine. As a result, the use of these classes of drugs in swine can potentially provide 162 selective pressure for the maintenance or emergence of resistant bacteria in humans (Marshall 163 and Levy 2011).

164 Although making a direct link between antimicrobial use in swine production and 165 antimicrobial-resistant infections in the human population is challenging, some studies have 166 demonstrated such a link. For example, outbreaks involving strains of multidrug-resistant 167 Salmonella enterica serotype Typhimurium DT104 in Denmark (Mølbak et al. 1999), S. enterica 168 serotype Typhimurium DT104 in England (Maguire et al. 1993), and Enterococcus faecium in 169 China (Lu et al. 2002) originated from swine herds.

170 Since 2006, the European Union has banned the use of antibiotics in food-producing 171 animals for the purpose of growth promotion (European Union 2005). In both Canada and the 172 United States, the government has recently implemented plans for a voluntary reduction in 173 antimicrobial use for the purpose of growth promotion in food-producing animals over an 174 expected three-year period (Health Canada 2014; United States Food and Drug Administration 175 2013). In the US, this is also intended to put in-feed antimicrobials under the veterinary feed 176 directive. Until these changes, however, a veterinarian's prescription was not generally required 177 to purchase antimicrobials for use in swine in most areas of North America. 


\section{Heavy metals}

Other agents with potential antimicrobial activity are also included in feeds given to

180 swine. In particular, heavy metals, namely zinc and copper, are frequently added to swine feeds

181 at levels ( $\mathrm{Cu}: 10$ to $250 \mathrm{mg} \mathrm{kg}^{-1}$ feed, $\mathrm{Zn}$ : 125 to $3000 \mathrm{mg} \mathrm{kg}^{-1}$ feed) which exceed dietary

182 requirements $\left(\mathrm{Cu}: 5\right.$ to $10 \mathrm{mg} \mathrm{kg}^{-1}$ feed; $\mathrm{Zn}: 50$ to $125 \mathrm{mg} \mathrm{kg}^{-1}$ feed; Jacela et al. 2010;

183 Jondreville et al. 2003). While zinc and copper are essential dietary elements that are required

184 by swine for a number of metabolic functions, higher concentrations are added to feed for their

185 ability to promote growth and control colibacillosis (Fairbrother et al. 2005; Hojberg et al. 2005).

186 Not only do zinc and copper mimic some of the growth promoting and disease

187 controlling effects of antibiotics, but they can also increase the abundance of antibiotic-resistance

188 determinants and resistant bacteria in the swine gut (Bednorz et al. 2013; Hölzel et al. 2012).

189 The reason for this phenomenon may be due to co-selection and co-resistance where antibiotic

190 resistance determinants are located on the same mobile genetic element as heavy metals

191 resistance genes (Baker-Austin et al. 2006; Frye et al. 2011). Cross-resistance, in the form of

192 efflux pumps that can export structurally different molecules from the bacterial cell may also be

193 a factor (Baker-Austin et al. 2006). Therefore, the extensive use of zinc and copper in swine

194 feeds may also help explain why antimicrobial resistance persists even in the absence of

195 antimicrobial exposure (Mathew et al. 2001; Pakpour et al. 2012; Stanton et al. 2011). An 196 association between the isolation of methicillin-resistant Staphylococcus aureus (MRSA) in 197 swine and the use of relatively high levels of zinc in swine diets has also been recently observed 198 (Amachawadi et al. 2015; Slifierz et al. 2015).

\section{Swine gut microbiota}


The mammalian gut is home to approximately $10^{14}$ bacterial cells and 500-1000 species

201 of bacteria, the majority of which are anaerobic and not easily cultured in the laboratory

202 (Lamendella et al. 2011; Sommer and Bäckhed 2013). It is difficult to reproduce not only the

203 environmental conditions but also the symbiotic relationships among microbes found in the gut

204 (Nocker et al. 2007). As a result, perhaps as little as 1\% of intestinal bacteria are cultivable

205 (Dowd et al. 2008). All bacteria found in the swine intestinal tract, however, are potentially

206 affected upon consumption of an antimicrobial agent. Antimicrobial growth promoters in

207 particular, tend not to be well absorbed in the gut and can act directly on the microbiota, mainly

208 on Gram-positive bacteria (Erik and Knudsen 2001).

209 The gastrointestinal tract of the pig contains a large and diverse number of

210 microorganisms, which are collectively termed the gut microbiota when referring solely to

211 microorganisms, or the gut microbiome when referring to the genomes of microorganisms in this

212 location, although sometimes these terms are used interchangeably (Lamendella et al. 2011;

213 Turnbaugh et al. 2007). The swine intestinal microbiota is not homogenous; rather it differs

214 based on the sample location, with significantly more microbial diversity and higher

215 concentrations of bacteria in the colon $\left(10^{10}\right.$ to $10^{12} \mathrm{CFU} \mathrm{g}^{-1}$ digesta $)$ compared to the ileum $\left(10^{8}\right.$

216 to $10^{9} \mathrm{CFU} \mathrm{g}^{-1}$ digesta), and in the ileum compared to the stomach and proximal small intestine

217 (10 $10^{3}$ to $10^{5} \mathrm{CFU} \mathrm{g}^{-1}$ digesta) (Dibner and Richards 2005; Leser et al. 2000).

218 The gastrointestinal tract of swine is generally thought to be sterile prior to birth, but it

219 rapidly becomes colonized with bacteria from the environment, diet, and sow (Dibner and

220 Richards 2005; Kim and Isaacson 2015). The age of the pigs is also an important factor, as

221 nursing piglets have a very different gut microbiota from post-weaned pigs (Holman and Chénier

222 2014; Mach et al. 2015). For example, the phylum Proteobacteria is more abundant prior to 
223 weaning (Holman and Chénier 2014; Zhao et al. 2015). The differences in the gut microbiota of

224 pre- vs. post-weaned piglets are driven largely by the shift in diet from an easily digestible sow's

225 milk to grain-based feed that occurs at weaning. The immune system of the pig is also relatively

226 immature at this time which may allow for the colonization of pathogenic bacteria (Lalles et al.

227 2007). Over time, the swine gut microbiota becomes increasingly more stable and as a result the

228 gut microbiota becomes more resistant to dietary perturbations (Holman and Chénier 2014; Kim

229 et al. 2012). The texture of the feed and granulometry (Mølbak et al. 2008), as well as the

230 sanitary conditions of the housing environment can also alter the gut microbiota, with pigs raised

231 under poor sanitation having been shown to shed more Lactobacillus (increase of $0.9 \log _{10} \mathrm{CFU}$

$232 \mathrm{~g}^{-1}$ feces) and Enterobacteriaceae (increase of $1.0 \log _{10} \mathrm{CFU} \mathrm{g} \mathrm{g}^{-1}$ feces) in their feces (Montagne

233 et al. 2010).

234 The gut microbiota is a vital component of a healthy animal. Bacteria in the colon

235 metabolize undigested carbohydrates into short-chain fatty acids which are then absorbed by the

236 host. In this way, intestinal bacteria help recover nutrients which would otherwise be lost

237 through excretion (Cummings and Macfarlane 1997; Laparra and Sanz 2010). Commensal gut

238 microorganisms also provide resistance against the colonization of pathogens through

239 competition for nutrients and binding sites on the host intestinal epithelium, as well as altering

240 the local intestinal environment with the production of volatile fatty acids, modified bile acids

241 and antimicrobial compounds (Allen and Stanton 2014; Gaskins 2001; Lalles et al. 2007). The

242 host immune system largely tolerates these commensal gut bacteria which also help stimulate

243 normal immunological development and homeostasis (Kelly et al. 2005; Sommer and Bäckhed

244 2013; Zoetendal et al. 2004). 
The mammalian gut microbiota is comprised largely of Bacteria, but Archaea, Protozoa,

246 viruses, and fungi are also present (Leser and Mølbak 2009; Sommer and Bäckhed 2013). The

247 majority of the swine gut microbiota is comprised of relatively few different phyla, namely the

248 Bacteroidetes and Firmicutes (Holman and Chénier 2014; Kim et al. 2011). At the genus level,

249 Prevotella, Lactobacillus, Treponema, Roseburia, and Streptococcus are among the most

250 abundant genera (Holman and Chénier 2014; Kim et al. 2011; Lamendella et al. 2011; Park et al.

251 2014). In the swine ileum, the microbiota is dominated almost entirely by Firmicutes at the

252 phylum level and Anaerobacter, Turicibacter, and Escherichia at the genus level (Looft et al.

$2532014 a)$.

254 Effect of antimicrobials on antimicrobial resistance in the cultivable swine gut microbiota

255 Traditionally, the effect of antimicrobials on the emergence of antimicrobial-resistant

256 bacterial strains has focused on pathogenic organisms such as Campylobacter spp., enterococci,

257 E. coli, and Salmonella. Antimicrobial resistance in these organisms in swine production has

258 recently been reviewed in detail elsewhere and therefore will not be discussed further (Barton

259 2014). However, antimicrobials do not only target pathogenic bacteria.

260 Dawson et al. (1984) conducted one of the first studies on the effect of antimicrobials on

261 antimicrobial resistance in the total anaerobic bacterial population in the swine gut. Pigs in this

262 study were fed either subtherapeutic $\left(27.5 \mathrm{mg} \mathrm{kg}^{-1}\right.$ feed $)$ or therapeutic $\left(220 \mathrm{mg} \mathrm{kg}^{-1}\right.$ feed $)$ levels

263 of chlortetracycline for 85 and 14 days respectively. Only the pigs fed therapeutic levels of

264 chlortetracycline had a significantly higher percentage of chlortetracycline-resistant anaerobes

265 (at 14 days), however, after 85 days all pigs, including the controls, excreted high levels of

266 chlortetracycline-resistant anaerobes (62-72\%; Dawson et al. 1984). 
Kalmokoff et al. (2011) also evaluated antimicrobial resistance in total anaerobes 268 isolated from the feces of pigs fed either tylosin (44 or $\left.88 \mathrm{mg} \mathrm{kg} \mathrm{feed}^{-1}\right)$ or virginiamycin (11 or

$26922 \mathrm{~kg} \mathrm{feed}^{-1}$ ) and recorded that all anaerobes were resistant to both antibiotics, even in the 270 absence of exposure. In addition to the potential co-selection from heavy metals in the diet or 271 even the use of disinfectants during cleaning, this likely reflects the long period of time that 272 antimicrobials have been used in swine production. As well, the fitness costs of carrying 273 antimicrobial resistance determinants may be variable or mitigated in some circumstances 274 (Andersson 2006).

275 Previously, we published a study examining the effect of the continuous administration of 276 subtherapeutic concentrations of tylosin (11 to $44 \mathrm{mg} \mathrm{kg}^{-1}$ feed) and chlortetracycline $\left(5.5 \mathrm{mg} \mathrm{kg}^{-}\right.$

$277{ }^{1}$ feed) in farrow-to-finish pigs on the level of resistance to these agents in total anaerobic 278 bacterial populations and on the detection and abundance of selected resistance genes (Holman 279 and Chénier 2013). Pigs that were fed tylosin-supplemented feed exhibited a rapid increase in 280 tylosin-resistant fecal anaerobes; $11.8 \%$ tylosin-resistant prior to and $89.6 \%$ after treatment. The 281 concentration of the macrolide resistant gene $\operatorname{erm}(\mathrm{B})$ was similarly affected, with a 10-fold 282 increase observed in tylosin-supplemented pigs. Despite a progressive decrease in tylosin 283 concentration (44 mg kg-1 feed to $22 \mathrm{mg} \mathrm{kg}^{-1}$ feed to $11 \mathrm{mg} \mathrm{kg}^{-1}$ feed) and a two-week 284 withdrawal period prior to shipping, neither tylosin-resistant anaerobes nor the concentration of $285 \operatorname{erm}(\mathrm{B})$ was significantly affected. Notably, the total number of anaerobes was not affected by 286 either antibiotic, only the resistant proportion was altered. Conversely, chlortetracycline, which 287 was administered at a lower dosage, had no measurable effect on either chlortetracycline 288 resistance in total anaerobes or on the abundance of selected tet genes (Holman and Chénier 289 2013). 


\section{Effect of antimicrobials on the swine gut microbiota using culture-independent methods}

The challenges associated with culturing gut-associated microorganisms have led to the

292 use of both single gene sequencing and metagenomic analysis. Typically, single gene

293 sequencing focuses on the 16S rRNA gene; one or more of its nine hypervariable regions is

294 amplified via PCR and then sequenced. Other highly conserved genes with regions of

295 variability, such as cpn60, may also be used (Hill et al. 2004). Metagenomics refers to the 296 analysis of all genetic material from a specific environment, rather than a single gene (Thomas et

297 al. 2012). This technology has the advantage of not requiring knowledge about the DNA 298 sequences in question and reduces some of the biases associated with PCR, although other 299 limitations may be associated with this technology (Poretsky et al. 2014).

$300 \quad 16 S$ rRNA gene sequencing-based methods

301 Hence, the effect of in-feed antimicrobials on the swine gut microbiota has been 302 investigated by several researchers using a number of culture-independent methods. Kalmokoff 303 et al. (2011) reported no impact on the swine fecal microbiota in commercial pigs fed either

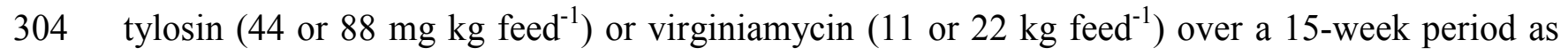
305 measured using both 16S rRNA gene DGGE (denaturaing gradient gel electrophoresis; V3 306 region) and near-full length 16S rRNA gene clone library analysis. Also using 16S rRNA gene 307 DGGE (V3 region), Collier et al. (2003) examined the effect of in-feed tylosin at $44 \mathrm{mg} \mathrm{kg}^{-1}$ feed 308 on the ileal microbiota of swine and observed a decrease in the number of DGGE bands 309 following 14 days of treatment, however, no differences were reported at day 21,28 , or 35 . The 310 authors also noted a decrease in total bacterial 16S rRNA gene abundance at days 14 and 21, 311 although not after 28 or 35 days. Of interest, was their finding that the relative proportion of 
312 Lactobacillus 16S rRNA gene sequences was more prevalent after tylosin treatment (Collier et 313 al. 2003).

314 Namkung et al. (2004) and Gong et al. (2008) also used 16S rRNA gene DGGE (V3 315 region) and reported that lincomycin $\left(110 \mathrm{mg} \mathrm{kg}^{-1}\right.$ feed) decreased microbial diversity in the ileal 316 microbiota compared with a basal diet over a four-week period, although not significantly so. 317 Similarly, Bosi et al. (2011) found that amoxicillin (600 mg kg feed), doxycycline (300 $\mathrm{mg} \mathrm{kg}^{-1}$ 318 feed), or tilmicosin (400 $\mathrm{mg} \mathrm{kg}^{-1}$ feed), did not have any effect on the jejunal microbiota of three319 week old pigs as measured using the Shannon index and DGGE band number. Total 320 enterobacteria and lactobacilli were also not affected by any of the three antibiotics. The average 321 daily gain of the pigs was improved by antibiotic supplementation in this study, although only in 322 the 0 to 7 day and 0 to 21 day periods (Bosi et al. 2011).

A DGGE-based study (V6-V8 regions) by Janczyk et al. (2007) observed a decrease in

324 both diversity and richness (Shannon index: 0.79 in antibiotic-treated pigs vs. 1.03 in untreated 325 pigs) in the ileal microbiota of 39-day old piglets that had been administered a single dose of 326 amoxicillin (15 $\mathrm{mg} \mathrm{kg}^{-1}$ body weight) intramuscularly at birth. In piglets fed chlortetracycline 327 for two weeks at $50 \mathrm{mg} \mathrm{kg}^{-1}$ feed following weaning, a significant change in the ileal microbiota 328 was recorded by Rettedal et al. (2009) in a study using 2050 sequences generated from the near329 full length 16S rRNA gene. These changes were largely associated with a decrease in 330 Lactobacillus johnsonii, Turicibacter, and an increase in Lactobacillus amylovorus. Through the 331 use of surrogate sows, these authors concluded that the antenatal environment had a much 332 greater impact on the ileal lumen microbiota compared to the postnatal environment (Rettedal et

333 al. 2009). Terminal restriction fragment length polymorphism was used by Thymann et al.

334 (2007) to determine that weaned pigs treated with amoxicillin (20 mg kg ${ }^{-1}$ feed and 
335 intramuscularly $8.75 \mathrm{mg} \mathrm{kg}^{-1}$ body weight per $12 \mathrm{~h}$ ) and $2500 \mathrm{mg} \mathrm{ZnO} \mathrm{kg}^{-1}$ feed had a lower

336 microbial diversity in the small intestine than untreated pigs (Thymann et al. 2007).

337 The effect of feeding high levels of $\mathrm{Zn}\left(3000 \mathrm{mg} \mathrm{kg}^{-1}\right.$ feed $)$ or $\mathrm{Cu}\left(250 \mathrm{mg} \mathrm{kg}^{-1}\right.$ feed $)$ for

338 two weeks post-weaning has also been found to reduce diversity of the ileal bacterial microbiota

339 while only $\mathrm{Cu}$ was reported to decrease the colonic microbiota diversity when evaluated by

340 DGGE (Namkung et al. 2006). In contrast, Perez and others (2011) observed no change in the

341 fecal microbiota of pigs fed these same concentrations of $\mathrm{Zn}$ or $\mathrm{Cu}$ as measured by DGGE band

342 numbers. The inconsistency among DGGE-based studies of the effect in-feed $\mathrm{Zn}$ on the swine

343 gut microbiota was further demonstrated by Pieper et al. (2012) who found that higher doses of

$344 \mathrm{Zn}$ (up to $2500 \mathrm{mg} \mathrm{kg}^{-1}$ feed) actually increased the number of DGGE bands in samples taken

345 from the ileal microbiota of post-weaned swine.

346 Quantitfication of 12 bacterial groups and five Lactobacillus spp. was carried out by

347 Starke et al. (2014) using real-time PCR to determine the effect of supplementing the diets of 348 post-weaned swine with high $\mathrm{Zn}$ concentrations (2425 $\mathrm{mg} \mathrm{kg}^{-1}$ feed) for 54 days, sampled at four

349 different gastrointestinal locations. None of the bacterial groups, with the exception of the 350 reduction of certain Lactobacillus spp. in the small intestine, were consstently altered during the

351 trial. Culture-based analysis has also indicated that lactobacilli are reduced in the stomach,

352 ileum, cecum, and colon of pigs that were fed $2500 \mathrm{mg} \mathrm{Zn} \mathrm{kg}^{-1}$ feed for 14 days post-weaning 353 (Højberg et al. 2005).

\section{High-throughput $16 S$ rRNA gene and metagenomic sequencing}

355 While the above methods allow for the relatively rapid visualization of large shifts in the 356 microbiota, they may miss more subtle changes. More recently, higher-resolution high357 throughput sequencing techniques have been employed to better understand the changes that take 
358 place in the swine gut microbiota in response to dietary antimicrobial supplementation (Table 1).

359 Depending upon the sequencing platform used, high-throughput sequencing methods can 360 generate millions to billions of sequences in a single run (Caporaso et al. 2012).

361 Using 454 pyrosequencing of the metagenome and the 16S rRNA gene (V3 region), 362 Looft and others (2012) investigated the effect of in-feed ASP250 administered to three post363 weaned pigs for three weeks on the abundance and diversity of antimicrobial resistance genes.

364 The diversity of antimicrobial resistance genes was increased as was the abundance of six 365 different classes of resistance genes in the medicated pigs. These resistance gene classes 366 included not only those which confer resistance to the administered antibiotics but also to 367 antibiotics not used in the study, suggesting potential co-selection of these resistance gene 368 classes (Looft et al. 2012). Genes associated with horizontal gene transfer (transposases), 369 virulence (P pilus), as well as energy production and conversion were also reported to be more 370 prevalent in the medicated swine metagenomes. In addition, ASP250 caused identifiable shifts 371 in the swine gut microbiota, including a decrease in the relative abundance of Bacteroidetes 372 along with an increase in Proteobacteria (from 1\% in non-medicated to $11 \%$ in medicated), most 373 of which were E. coli (Looft et al. 2012). The bacterial community structure was also changed 374 following 14 days of ASP250 supplementation in the diet as measured using the Bray-Curtis 375 index (Looft et al. 2012). However, this effect did not extend to carbadox-treated (10 to $50 \mathrm{mg}$ $376 \mathrm{~kg}^{-1}$ feed) pigs in a similar study (Allen et al. 2011).

377 In this earlier study, Allen et al. (2011) determined that ASP250 altered both the fecal 378 bacterial microbiota as well as the fecal bacteriophage community in pigs fed ASP250 for 14 379 days beginning at 77 days of age. In this work, both metagenomic and the 16S rRNA gene (V1 380 to V3 region) libraries were sequenced using 454 pyrosequencing. The diversity of the bacterial 
381 gut microbiota was also diminished by ASP250 supplementation and the viromes of these pigs

382 contained more integrase genes, indicating that antibiotics may induce prophages. A decrease in

383 the relative abundance of the genera Coprococcus, Succinivibrio, Streptococcus, Treponema, and

384 Turicibacter was also observed in the ASP250 supplemented pigs (Allen et al. 2011).

385 A recent study by Looft et al. (2014b) used 454 pyrosequencing of the V1-V3 regions of

386 the 16S rRNA gene to examine the effect of carbadox (50 $\mathrm{mg} \mathrm{kg}^{-1}$ feed $)$ on the gut microbiota of

387 six week old pigs over a three-week period followed by a 42-day withdrawal phase. These

388 authors reported decreased bacterial richness and diversity in carbadox-fed pigs during the first

389 four days of treatment as well as significant changes in the bacterial community structure. In

390 particular, the relative abundance of the Bacteroidetes phylum and the Prevotella genus were

391 most notably increased during this time period, as were the genera Roseburia, Faecalibacterium,

392 and Asteroleplasma. Looft et al. (2014b) suggest that Prevotella, Roseburia, and

393 Faecalibacterium may provide growth benefits to the host through the production of short chain

394 fatty acids such as butyrate. Carbadox, however, did not induce changes in the medicated vs.

395 non-medicated pigs after 7, 14, or 21 days of treatment demonstrating the resilience of the swine

396 gut microbiota (Looft et al. 2014b). Interestingly, the fecal bacterial communities of the non-

397 medicated and medicated pigs diverged from one another again in the 21 to 42-day portion of the

398 withdrawal phase, although diversity metrics remained unchanged (Looft et al. 2014b). A

399 similar phenomenon has recently been reported in pigs that received a single injection of

400 tulathromycin (a macrolide antibiotic) at four days of age at $2.5 \mathrm{mg} \mathrm{kg}^{-1}$ body weight (Schokker

401 et al. 2015). This study used a DNA microarray, together with 16S rRNA gene sequences, to

402 determine that the jejunal microbiota of pigs injected with tulathromycin was altered in

403 comparison with untreated pigs only at 176 days of age but not at 55 days (Schokker et al. 2015). 
Other studies using high-throughput sequencing have reported no obvious alterations due

405 to in-feed antibiotic supplementation. 454 pyrosequencing of the 16S rRNA gene (V1-V3

406 regions) was also used by Poole et al. (2013) to investigate the effect of $50 \mathrm{mg}$ of

407 chlortetracycline $\mathrm{kg}^{-1}$ feed on the fecal microbiota of post-weaned swine over a 28-day period.

408 These authors found that chlortetracycline supplementation had no effect on bacterial diversity

409 and richness or on community structure diversity. However, the lack of significant effects could

410 have been a result of the relatively small number of pigs used in the study (two pigs per

411 treatment). Similarly, Kim et al. (2012) documented no difference at the bacterial phylum or

412 class-levels in 10 pigs continuously fed either tylosin (44 $\mathrm{mg} \mathrm{kg}^{-1}$ feed) or a control, antibiotic-

413 free diet, for 12 weeks starting at 10 weeks of age. These researchers sequenced the V3 region of

414 the 16S rRNA gene using 454 pyrosequencing (Kim et al. 2012). There were also no

415 identifiable changes in bacterial richness and diversity, or community structure metrics, although

416 the swine gut microbiota may have already been well established and relatively stable at this

417 stage of production ( $>10$ weeks). However, alterations in the relative abundance at the genus

418 and OTU-levels were observed. Prevotella and Lactobacillus were among six genera that were

419 more abundant in tylosin-fed pigs.

420 Recently, we used Illumina sequencing of the V4 region of the 16S rRNA gene to

421 investigate the effect of subtherapeutic levels of in-feed tylosin and chlortetracycline over a 19-

422 week period (Holman and Chénier 2014). While archaeal and bacterial diversity and richness in

423 pigs fed tylosin (11 to $44 \mathrm{mg} \mathrm{kg}^{-1}$ feed) starting at weaning was not altered compared to controls,

424 tylosin administration did result in numerous shifts at the phylum, genus, and OTU-levels. The

425 relative abundance of the genera Akkermansia, Coprococcus, and Streptococcus was enriched in

426 tylosin-fed pigs while Bacteroidetes and the genera Succinivibrio and Anaerovibrio were 
427 reduced. With the exception of the Coprococcus genus, however, these alterations in the major

428 ( $>0.1 \%$ of sequences) phyla and genera were not sustained from one sampling time to the next,

429 indicating that the dominant taxa are adaptable or resilient to perturbations by long-term

430 antibiotic administration. The overall community structure was also changed by in-feed tylosin

431 as measured using weighted UniFrac, which takes into account OTU abundance. These results

432 were not replicated in the chlortetracycline $\left(5.5 \mathrm{mg} \mathrm{kg}^{-1}\right.$ feed) pigs, although the relative 433 abundance of specific taxa such as Firmicutes and Lactobacillus were temporally altered

434 (Holman and Chénier 2014).

435 Looft et al. 2014 (2014a) combined 454 pyrosequencing of the 16S rRNA gene with 436 metagenomic analysis to monitor the impact of ASP250 on the ileal, cecal, colonic, and fecal 437 microbiota of three-month old pigs over a two-week period. It was found that changes in 438 bacterial taxa due to ASP250 administration were restricted to a specific location in the pig 439 gastrointestinal tract, while other changes occurred in multiple locations. For example, 440 Helicobacter was only reduced in the cecum and Turicibacter in the colon of ASP250-treated 441 pigs. Escherichia were increased in all gut locations in medicated pigs, most notably in the 442 lumen and mucosa of the ileum. The proportion of the genera Treponema and Streptococcus 443 were both diminished in the cecum and colon. Interestingly, although 12 antibiotic resistance 444 genes were differentially more abundant in the ASP250 pigs, 8 antibiotic resistance genes were 445 more abundant in the untreated pigs (Looft et al. 2014a).

446 Using 454 pyrosequencing of the V3-V5 region of the 16S rRNA gene, researchers in 447 China (Sun et al. 2014) evaluated the effect of feeding lincomycin hydrochloride (500 $\mathrm{mg} \mathrm{kg}^{-1}$ 448 feed), chlortetracycline (100 mg kg${ }^{-1}$ feed), and amoxicillin (500 mg kg-1 feed) to sows before 449 farrowing over a 12 day period. These authors reported a significant decrease in the relative 
450 abundance of Proteobacteria after treatment, in particular Escherichia/Shigella which were 451 reduced by $40 \%$. The Streptococcus genus was also reduced in the medicated sows whereas 452 Treponema, Enterococcus, and Staphylococcus were temporarily enriched. It should be noted 453 that in total, although nine samples were pooled into one composite sample, only one composite 454 sample was used per time point. Also, this treatment represents a relatively high concentration of 455 antibiotics being added to feed, at least compared to levels typically used in North America. Sun 456 et al. (2014) also used real-time PCR in this work and they observed greater numbers of 457 aminoglycoside, lincomycin, macrolide, and tetracycline resistance genes following antibiotic 458 treatment.

459 Two separate studies by Vahjen et al. $(2010 ; 2011)$ have examined the effect of $3000 \mathrm{mg}$ $460 \mathrm{Zn} \mathrm{kg}^{-1}$ feed on the ileal microbiota of post-weaned swine using pyrosequencing. At the genus461 level, Weissella, Leuconostoc, and Streptococcus were all increased in pigs receiving high levels 462 of Zn, while Sarcina was reduced (Vhajen et al. 2010). In the $2^{\text {nd }}$ study, bacterial diversity and 463 richness were reported to be enhanced in the high $\mathrm{Zn}$ dosage pigs. Species of Weisella and 464 Leuconostoc were again found to be more relatively abundant in the pigs fed high doses of $\mathrm{Zn}$ 465 and the proprotion of Lactobacillus reuteri and Sarcina ventriculi was decreased in these pigs 466 (Vhajen et al. 2011).

467 Effect of antimicrobial use on antimicrobial resistance determinants in the swine gut 468 microbiota

In addition to those studies already discussed, several other researchers have also 470 investigated the association of antimicrobial use and the abundance and detection of 471 antimicrobial resistance genes in swine feces and manure. In China, Zhu et al. (2013) detected a 472 total of 149 different antibiotic resistance genes in swine manure and composted manure from 
473 farms where at least six different antimicrobials were used as in-feed growth promoters and

474 several more were used for therapeutic reasons. The abundance of bla $\mathrm{TEM}$ genes conferring

475 resistance to ampicillin increased in the feces of pigs given ampicillin (20 $\mathrm{mg} \mathrm{kg}^{-1}$ body weight)

476 either orally or via intramuscular injection (Bibbal et al. 2007). A recent study by Agga et al.

477 (2015) found a higher abundance of the tet(A) gene in the feces of pigs fed $550 \mathrm{mg} \mathrm{kg}^{-1}$ feed

478 post-weaning, although the abundance of tet(B) was not affected.

Similar to studies that measure phenotypic resistance to antimicrobials in anaerobic

480 bacteria, there is a wide dissemination of antimicrobial resistance determinants among pigs in

481 modern production facilities even in the absence of antimicrobial exposure (Pakpour et al. 2012;

482 Holman and Chénier 2013; Agga et al. 2015; Kalmokoff et al. 2011). In particular, the

483 tetracycline resistance genes $\operatorname{tet}(\mathrm{M}), \operatorname{tet}(\mathrm{O}), \operatorname{tet}(\mathrm{Q})$, and $\operatorname{tet}(\mathrm{X})($ Agga et al. 2015; Barkovskii and

484 Bridges 2012; Holman and Chénier 2013) and the macrolide resistance genes $\operatorname{erm}(\mathrm{B}), \operatorname{erm}(\mathrm{F})$,

485 and erm(G) (Holman and Chénier 2013; Kalmokoff et al. 2011; Looft et al. 2012) are frequently

486 detected in pigs not directly exposed to antimicrobials.

487 The ubiquitous presence of these genes among antimicrobial-free pigs means that a 488 reduction in antimicrobial use in swine production will likely not immediately reduce 489 antimicrobial resistance in the gut microbiota of pigs. The complexity of this issue has been

490 demonstrated in Denmark where antimicrobial growth promoters were first banned in weanling 491 pigs in 1999 and in all pigs by 2000. While overall antimicrobial use has decreased in Denmark, 492 antimicrobial resistance in swine gut bacteria has largely persisted (Jensen and Hayes 2014). 493 This may be a result of the continued use of therapeutic levels of some antimicrobials and/or 494 agents that may co-select for resistance or provide cross-resistance such as heavy metals and 495 disinfectants (Hasman et al. 2006; Yazdankhah et al. 2014). At the same time, a reduction in 
496 macrolide use in swine in Denmark has resulted in a lower prevalence of macrolide-resistant

497 Campylobacter spp. (Alban et al. 2008).

498 Conclusions

499 Antimicrobials are used in swine production for a variety of purposes including animal 500 welfare, disease treatment, and growth promotion. It is well established that the use of these 501 antimicrobial agents helps provide the necessary selective pressure to maintain and increase the 502 abundance and dissemination of antimicrobial-resistant bacteria and resistance determinants. 503 Antimicrobial resistance, however, can also persist in the swine gut microbiota in the absence of 504 antimicrobial exposure. For this reason, the benefits of using relatively high levels of heavy 505 metals in swine diets should also be examined.

506 It is hoped that by characterizing the response of the swine gut microbiota to 507 antimicrobials, alternative agents such as prebiotics, probiotics, or other feed additives can be 508 developed to replace or reduce the use of antimicrobials. Although a number of studies have 509 now been conducted on the swine gut microbiota following antimicrobial perturbation using

510 high-throughput sequencing methods, no clear pattern has emerged in terms of the alteration of 511 specific bacterial genera or species. For example, the relative abundance of the lactic acid 512 bacterial genera Lactobacillus and Streptococcus, as well as Coprococcus, has been reported to 513 be both increased and reduced following in-feed antibiotic administration (Allen et al. 2011; 514 Holman and Chénier 2014; Looft et al. 2014a; Looft et al. 2014b). The same is true for the 515 phylum Bacteroidetes (Holman and Chénier 2014; Looft et al. 2014b; Sun et al. 2014).

516 These differences may be due to genetic and environmental factors (e.g. commercial vs. 517 research farm setting) as well as the experimental design of each study in relation to the age of 518 the pigs and the type and dosage of antibiotic used. In addition, the analytical methods and 
519 sequencing platforms used, as well as the choice of 16S rRNA variable region that is sequenced,

520 can all influence study outcomes. Nonetheless, the resilience of the swine gut microbiota to

521 long-term changes due to the administration of antimicrobials is apparent. Older pigs also

522 appear to exhibit fewer changes in their gut microbiota compared with younger swine in

523 response to in-feed antibiotics. This early growth stage also is also the time period where

524 antibiotics tend to be most effective in improving feed efficiency and/or growth rate. Rare

525 bacterial taxa, which are frequently ignored or removed during sequence analysis, may have a

526 larger role in the swine gut microbiota following antibiotic exposure than is currently known.

527 This also includes bacterial subspecies diversity which is undetectable with current sequencing

528 technologies (Allen and Stanton 2014). Finally, it is also possible that antibiotics have a positive

529 growth effect on the host that is independent of the gut microbiota (Niewold 2007).

530 The reporting of growth rate data in these types of studies might also help identify those

531 cases where microbial changes should be expected in response to antimicrobial supplementation.

532 As well, although feces are often the sample of choice because it allows for the continuous

533 sampling from a single animal, it may not accurately represent the changes that occur in the

534 entire swine gastrointestinal tract in response to antimicrobial administration.

\section{References}

537 Agga, G.E., Scott, H.M., Vinasco, J., Nagaraja, T.G., Amachawadi, R.G., Bai, J., Norby, B., 538 Renter, D.G., Dritz, S.S., Nelssen, J.L. and Tokach, M.D. 2015. Effects of 539 chlortetracycline and copper supplementation on the prevalence, distribution, and 540 quantity of antimicrobial resistance genes in the fecal metagenome of weaned pigs. Prev. $541 \quad$ Vet. Med. doi:10.1016/j.prevetmed.2015.02.008. 
542 Akwar, H.T., Poppe, C., Wilson, J., Reid-Smith, R.J., Dyck, M., Waddington, J., Shang, D., and 543 McEwen, S.A. 2008. Prevalence and patterns of antimicrobial resistance of fecal Escherichia coli among pigs on 47 farrow-to-finish farms with different in-feed

Alban, L., Nielsen, E.O., Dahl, J. 2008. A human health risk assessment for macrolide-resistant Campylobacter associated with the use of macrolides in Danish pig production. Prev. Vet. Med. 83(2):115-29. doi:10.1016/j.prevetmed.2007.06.006.

Allen, H.K., Levine, U.Y., Looft, T., Bandrick, M., and Casey, T.A. 2013. Treatment, promotion, commotion: antibiotic alternatives in food-producing animals. Trends Microbiol. 21(3): 114-119. doi: 10.1016/j.tim.2012.11.001.

Allen, H.K., Looft, T., Bayles, D.O., Humphrey, S., Levine, U.Y., Alt, D., and Stanton, T.B. 2011. Antibiotics in feed induce prophages in swine fecal microbiomes. mBio 2(6): e00260-00211. doi: 10.1128/mBio.00260-11.

Allen HK, Stanton TB. Altered egos: antibiotic effects on food animal microbiomes. 2014. Annu. Rev. Microbiol 68:297-315. doi:10.1146/annurev-micro-091213-113052.

557 Amachawadi, R.G., Scott, H.M., Nitikanchana, S., Vinasco, J., Tokach, M.D., Dritz, S.S., Nelssen, J.L., Goodband, R.D., Nagaraja, T.G. 2015. Nasal carriage of mecA-positive methicillin-resistant Staphylococcus aureus in pigs exhibits dose-response to zinc supplementation. Foodborne Pathog. Dis. 12(2):159-63. doi:10.1089/fpd.2014.1851.

Andersson, D.I. 2006. The biological cost of mutational antibiotic resistance: any practical conclusions? Curr. Opin. Microbiol. 9(5): 461-465. 
563 Barkovskii, A.L., Bridges, C. 2012. Persistence and profiles of tetracycline resistance genes in

564

565

566

567

568

569

570

571

572

573

574

575

576

577

578

579

580

581

582

583

584

585

swine farms and impact of operational practices on their occurrence in farms' vicinities. Water Air Soil Pollut. 223:49-62. doi: 10.1007/s11270-011-0838-1.

Barton, M.D. 2014. Impact of antibiotic use in the swine industry. Curr. Opin. Microbiol. 19: 915. doi: 10.1016/j.mib.2014.05.017.

Bednorz, C., Oelgeschläger, K., Kinnemann, B., Hartmann, S., Neumann, K., Pieper, R., Bethe, A., Semmler, T., Tedin, K., Schierack, P., Wieler, L.H., Guenther, S. 2013. The broader context of antibiotic resistance: zinc feed supplementation of piglets increases the proportion of multi-resistant Escherichia coli in vivo. Int. J. Med. Microbiol. 303(67):396-403. doi: 10.1016/j.jimm.2013.06.004.

Bibbal D, Dupouy V, Ferre JP, Toutain PL, Fayet O, Prere MF et al. (2007). Impact of three ampicillin dosage regimens on selection of ampicillin resistance in Enterobacteriaceae and excretion of blaTEM genes in swine feces. Appl. Environ. Microbiol. 73:4785-4790.

Bosi, P., Merialdi, G., Scandurra, S., Messori, S., Bardasi, L., Nisi, I., Russo, D., Casini,, L., Trevisi, P. 2011. Feed supplemented with 3 different antibiotics improved food intake and decreased the activation of the humoral immune response in healthy weaned pigs but had differing effects on intestinal microbiota. J. Anim. Sci. 89(12):4043-53. doi: 10.2527/jas.2010-3311.

Butaye, P., Devriese, L.A., and Haesebrouck, F. 2003. Antimicrobial growth promoters used in animal feed: effects of less well known antibiotics on gram-positive bacteria. Clin. Microbiol. Rev. 16(2): 175-188.

Canadian Food Inspection Agency. 2015. Compendium of Medicating Ingredient Brochures. http://www.inspection.gc.ca/animals/feeds/medicating-ingredients/mib/eng 
Caporaso, J.G., Lauber, C.L., Walters, W.A., Berg-Lyons, D., Huntley, J., Fierer, N., Owens, S.M., Betley, J., Fraser, L., Bauer, M., Gormley, N., Gilbert, J.A., Smith, G., Knight, R. 2012. Ultra-high-throughput microbial community analysis on the Illumina HiSeq and MiSeq platforms. ISME J. 6(8):1621-4. doi: 10.1038/ismej.2012.8.

Collier, C., Smiricky-Tjardes, M., Albin, D., Wubben, J., Gabert, V., Deplancke, B., Bane, D., Anderson, D., and Gaskins, H. 2003. Molecular ecological analysis of porcine ileal microbiota responses to antimicrobial growth promoters. J. Anim. Sci. 81(12):3035-3045.

Cromwell, G.L. 2002. Why and how antibiotics are used in swine production. Anim Biotechnol

$$
\text { 13(1):7-27. }
$$

Cummings, J.H., and Macfarlane, G.T. 1997. Colonic microflora: nutrition and health. Nutrition $13(5): 476-478$.

Dawson, K.A., Langlois, B.E., Stahly, T.S., Cromwell, G.L. 1984. Antibiotic resistance in anaerobic and coliform bacteria from the intestinal tract of swine fed therapeutic and subtherapeutic concentrations of chlortetracycline. J. Anim. Sci. 58(1):123-31.

Deckert, A., Gow, S., Rosengren, L., Leger, D., Avery, B., Daignault, D., Dutil, L., Reid-Smith, 602 R., and Irwin, R. 2010. Canadian integrated program for antimicrobial resistance surveillance (CIPARS) farm program: results from finisher pig surveillance. Zoonoses Public Health 57(s1):71-84. doi: 10.1111/j.1863-2378.2010.01356.x.

Dibner, J., and Richards, J. 2005. Antibiotic growth promoters in agriculture: history and mode of action. Poult. Sci. 84(4):634-643.

607 Dowd, S.E., Sun, Y., Wolcott, R.D., Domingo, A., and Carroll, J.A. 2008. Bacterial tag-encoded 608 FLX amplicon pyrosequencing (bTEFAP) for microbiome studies: bacterial diversity in 
the ileum of newly weaned Salmonella-infected pigs. Foodborne Pathog. Dis. 5(4):459472.

611 Dunlop, R., McEwen, S., Meek, A., Clarke, R., Black, W., and Friendship, R. 1998. Associations among antimicrobial drug treatments and antimicrobial resistance of fecal Escherichia coli of swine on 34 farrow-to-finish farms in Ontario, Canada. Prev. Vet. Med. 34(4):283-305.

Erik, K., and Knudsen, B. 2001. Development of antibiotic resistance and options to replace antimicrobials in animal diets. Proc. Nutr. Soc. 60(03):291-299.

617 European Union. 2005. Ban on antibiotics as growth promoters in animal feed enters into effect (1831/2003/EC). http://europa.eu/rapid/press-release_IP-05-1687_en.htm. Accessed July $20,2015$.

Fairbrother, J.M., Nadeau, E., Gyles, C.L. 2005. Escherichia coli in postweaning diarrhea in pigs: an update on bacterial types, pathogenesis, and prevention strategies. Anim. Health Res. Rev. 6(1):17-39. doi: 10.1079/AHR2005105.

Food and Agriculture Organization. 2010. Agricultural production. http://www.fao.org/economic /ess/ess-publications/ess-yearbook/ess-yearbook2010/yearbook2010-production/en. Accessed July 20, 2015.

Food and Agriculture Organization. 2012. FAO Statistical Yearbook 2012: World Food and Agriculture. http://www.fao.org/docrep/015/i2490e/i2490e00.htm. Accessed July 20, 2015.

Food and Agriculture Organization. 2014. Food Outlook: Biannual Report on Global Food Markets. http://www.fao.org/3/a-i4136e.pdf. Accessed July 20, 2015. 
631 Fluit, A., Van der Bruggen, J., Aarestrup, F., Verhoef, J., and Jansen, W. 2006. Priorities for antibiotic resistance surveillance in Europe. Clin. Microbiol. Infect. 12(5):410-417.

Friendship, R., Prescott, J. F. 2006. Drug therapy and prophylaxis. In: Straw BE (ed). Diseases of

635

636

637

638

639

640

641

642

643

644

645

646

647

648

649

650

651

652

653 Swine, 9th ed. Blackwell Publishing: Ames, Iowa. pp 1131-1143.

Frost, L.S., Leplae, R., Summers, A.O., and Toussaint, A. 2005. Mobile genetic elements: the agents of open source evolution. Nat. Rev. Microbiol. 3(9):722-732. doi:10.1038/nrmicro1235

Frye, J.G., Lindsey, R.L., Meinersmann, R.J., Berrang, M.E., Jackson, C.R., Englen, M.D., Turpin, J.B., and Fedorka-Cray, P.J. 2011. Related antimicrobial resistance genes detected in different bacterial species co-isolated from swine fecal samples. Foodborne Pathog. Dis. 8(6):663-679. doi: 10.1089/fpd.2010.0695

Gaskins, H. 2001. Intestinal bacteria and their influence on swine growth. In: Southern, AJ (ed). Swine Nutrition. CRC Press LLC: Florida. pp 585-608.

Gellin, G., Langlois, B.E., Dawson, K.A., and Aaron, D.K. 1989. Antibiotic resistance of gramnegative enteric bacteria from pigs in three herds with different histories of antibiotic exposure. Appl. Environ. Microbiol. 55(9):2287-2292.

Gong, J., Yu, H., Liu, T., Li, M., Si, W., de Lange, C.F., and Dewey, C. 2008. Characterization of ileal bacterial microbiota in newly-weaned pigs in response to feeding lincomycin, organic acids or herbal extract. Livest. Sci. 116(1):318-322. doi:10.1016/j.livsci.2008.01.001

Hasman, H., Kempf, I., Chidaine, B., Cariolet, R., Ersbøll, A.K., Houe, H., Bruun Hansen, H.C., Aarestrup, F.M. 2006. Copper resistance in Enterococcus faecium, mediated by the tcrB gene, is selected by supplementation of pig feed with copper sulfate. Appl. 
Environ. Microbiol. 72(9):5784-9. doi: 10.1128/AEM.02979-05.

655

656

657

658

659

660

661

662

663

664

665

666

667

668

669

670

671

672

673

674

Health Canada. 2014. Notice to stakeholders: Collaborative efforts to promote the judicious use of medically-important antimicrobial drugs in food animal production. http://www.hcsc.gc.ca/dhp-mps/vet/antimicrob/amr-notice-ram-avis-20140410-eng.php. Accessed July 20, 2015.

Hill, J.E., Penny, S.L., Crowell, K.G., Goh, S.H., and Hemmingsen, S.M. 2004. cpnDB: a chaperonin sequence database. Genome Res. 14(8):1669-1675. doi: $10.1101 /$ gr.2649204

Højberg, O., Canibe, N., Poulsen, H.D., Hedemann, M.S., Jensen, B.B. 2005. Influence of dietary zinc oxide and copper sulfate on the gastrointestinal ecosystem in newly weaned piglets. Appl. Environ. Microbiol. 71(5):2267-77. doi: 10.1128/AEM.71.5.22672277.2005 .

Holman, D.B., and Chénier, M.R. 2013. Impact of subtherapeutic administration of tylosin and chlortetracycline on antimicrobial resistance in farrow-to-finish swine. FEMS Microbiol. Ecol. 85(1):1-13. doi: 10.1111/1574-6941.12093.

Holman, D.B., and Chénier, M.R. 2014. Temporal changes and the effect of subtherapeutic concentrations of antibiotics in the gut microbiota of swine. FEMS Microbiol. Ecol. 90(3):599-608. doi: 10.1111/1574-6941.12419

Holt, J., van Heugten, E., Graves, A., See, M., and Morrow, W. 2011. Growth performance and antibiotic tolerance patterns of nursery and finishing pigs fed growth-promoting levels of antibiotics. Livest. Sci. 136(2):184-191. doi:10.1016/j.livsci.2010.09.007. 
675 Hölzel, C.S., Müller, C., Harms, K.S., Mikolajewski, S., Schäfer, S., Schwaiger, K., Bauer, J. 676 2012. Heavy metals in liquid pig manure in light of bacterial antimicrobial resistance. Environ. Res. 113:21-7. doi: 10.1016/j.envres.2012.01.002.

678 Hvistendahl, M. 2012. China takes aim at rampant antibiotic resistance. Science 336(6083):795795. doi: $10.1126 /$ science.336.6083.795.

680 Jacela, J.Y., DeRouchey, J.M., Tokach, M.D., Goodband, R.D., Nelssen, J.L., Renter, D.G., Dritz, S.S. 2010. Feed additives for swine: fact sheets-prebiotics and probiotics, and phytogenics. J. Swine Health Prod. 18:132-136.

Janczyk, P., Pieper, R., Souffrant, W.B., Bimczok, D., Rothkötter, H.J., Smidt, H. 2007. Parenteral long-acting amoxicillin reduces intestinal bacterial community diversity in piglets even 5 weeks after the administration. ISME J. 1(2):180-3.

Jin, Z., Yang, Y., Choi, J., Shinde, P., Yoon, S., Hahn, T.-W., Lim, H., Park, Y., Hahm, K., and doi:10.1038/ismej.2007.29

Jensen, H.H., Hayes, D.J. 2014. Impact of Denmark's ban on antimicrobials for growth promotion. Curr. Opin. Microbiol. 19:30-6. doi: 10.1016/j.mib.2014.05.020.

694 Jondreville, C., Revy, P., and Dourmad, J. 2003. Dietary means to better control the 695 Joo, J. 2008. Effects of potato (Solanum tuberosum L. cv. Golden valley) protein having antimicrobial activity on the growth performance, and intestinal microflora and morphology in weanling pigs. Anim. Feed Sci. Technol. 140(1):139-154. doi:10.1016/j.anifeedsci.2007.12.006. environmental impact of copper and zinc by pigs from weaning to slaughter. Livest. Prod. Sci. 84(2):147-156. doi:10.1016/j.livprodsci.2003.09.011. 
697 Jukes, T.H., Stokstad, E., Tayloe, R., Cunha, T., Edwards, H., and Meadows, G. 1950. Growth698 promoting effect of aureomycin on pigs. Arch. Biochem. 26: 324-325.

699 Kalmokoff, M., Waddington, L., Thomas, M., Liang, K.L., Ma, C., Topp, E., Dandurand, U.D., 700 Letellier, A., Matias, F., and Brooks, S. 2011. Continuous feeding of antimicrobial 701 growth promoters to commercial swine during the growing/finishing phase does not modify faecal community erythromycin resistance or community structure. J. Appl. Microbiol. 110(6):1414-1425. doi: 10.1111/j.1365-2672.2011.04992.x.

Kelly, D., Conway, S., and Aminov, R. 2005. Commensal gut bacteria: mechanisms of immune modulation. Trends Immunol 26(6):326-333. doi:10.1016/j.it.2005.04.008.

Kim, H.B., Borewicz, K., White, B.A., Singer, R.S., Sreevatsan, S., Tu, Z.J., and Isaacson, R.E. 2011. Longitudinal investigation of the age-related bacterial diversity in the feces of

Kim, H.B., Borewicz, K., White, B.A., Singer, R.S., Sreevatsan, S., Tu, Z.J., and Isaacson, R.E. 2012. Microbial shifts in the swine distal gut in response to the treatment with antimicrobial growth promoter, tylosin. Proc. Natl. Acad. Sci. USA 109(38):15485-

Kim, H.B., Isaacson, R.E. 2015. The pig gut microbial diversity: Understanding the pig gut microbial ecology through the next generation high throughput sequencing. Vet. Microbiol. 177(3-4):242-251. doi: 10.1016/j.vetmic.2015.03.014. pigs around weaning. Proc. Nutr. Soc. 66(02):260-268. doi: $10.1017 / \mathrm{S} 0029665107005484$. 
719 Lamendella, R., Santo Domingo, J.W., Ghosh, S., Martinson, J., and Oerther, D.B. 2011. 720 Comparative fecal metagenomics unveils unique functional capacity of the swine gut. 721 BMC Microbiol. 11(1):103. doi: 10.1186/1471-2180-11-103.

722 Laparra, J.M., and Sanz, Y. 2010. Interactions of gut microbiota with functional food 723 components and nutraceuticals. Pharmacol. Res. 61(3): 219-225. doi:

725

726

727

728

729

730

731

732

733

734

735

736

737

738

739

740 10.1016/j.phrs.2009.11.001

Leser, T.D., Lindecrona, R.H., Jensen, T.K., Jensen, B.B., and Møller, K. 2000. Changes in bacterial community structure in the colon of pigs fed different experimental diets and after infection with Brachyspira hyodysenteriae. Appl. Environ. Microbiol. 66(8): 32903296. doi: 10.1128/AEM.66.8.3290-3296.2000.

Leser, T.D., and Mølbak, L. 2009. Better living through microbial action: the benefits of the mammalian gastrointestinal microbiota on the host. Environ. Microbiol. 11(9): 21942206. doi: 10.1111/j.1462-2920.2009.01941.x.

Levy, S.B., and Marshall, B. 2004. Antibacterial resistance worldwide: causes, challenges and responses. Nat. Med. 10: S122-S129. doi:10.1038/nm1145.

Livermore, D.M., Blaser, M., Carrs, O., Cassell, G., Fishman, N., Guidos, R., Levy, S., Powers, J., Norrby, R., and Tillotson, G. 2011. Discovery research: the scientific challenge of finding new antibiotics. J. Antimicrob. Chemother. 66(9): 1941-1944. doi: $10.1093 / \mathrm{jac} / \mathrm{dkr} 262$.

Looft, T., Allen, H.K., Cantarel, B.L., Levine, U.Y., Bayles, D.O., Alt, D.P., Henrissat, B., and Stanton, T.B. 2014a. Bacteria, phages and pigs: the effects of in-feed antibiotics on the microbiome at different gut locations. ISME J. 8(8):1566-76. doi: 10.1038/ismej.2014.12. 
741 Looft, T., Allen, H.K., Casey, T.A., Alt, D.P., and Stanton, T.B. 2014b. Carbadox has both 742 temporary and lasting effects on the swine gut microbiota. Front. Microbiol. 5:276. doi: 10.3389/fmicb.2014.00276.

744 Looft, T., Johnson, T.A., Allen, H.K., Bayles, D.O., Alt, D.P., Stedtfeld, R.D., Sul, W.J., 745 Stedtfeld, T.M., Chai, B., and Cole, J.R. 2012. In-feed antibiotic effects on the swine intestinal microbiome. Proc. Natl. Acad. Sci. 109(5):1691-1696. doi: 10.1073/pnas.11202381.

Lu, H-Z, Weng X-H, Li H, Yin Y-K, Pang M-Y, Tang Y-W. 2002. Enterococcus faecium-related outbreak with molecular evidence of transmission from pigs to humans. J. Clin. Microbiol. 40(3):913-917. doi:10.1128/JCM.40.3.913-917.2002.09.

MacDonald, J.M., and McBride, W.D. 2009. The transformation of US livestock agriculture 752 scale, efficiency, and risks. USDA ERS. http://www.ers.usda.gov/publications/eibeconomic-information-bulletin/eib43.aspx. Accessed July 18, 2015.

754 Mach, N., Berri, M., Estellé, J., Levenez, F., Lemonnier, G., Denis, C., Leplat, J.J., Chevaleyre, C., Billon, Y., Doré, J., Rogel-Gaillard, C., Lepage, P. 2015. Early-life establishment of

Maguire H.C., Codd, A.A., Mackay, V.E., Rowe, B., Mitchell, E. 1993. A large outbreak of 759 human salmonellosis traced to a local pig farm. Epidemiol. Infect. 110(2):239-46. doi: $10.1017 / \mathrm{S} 0950268800068151$.

761 Marshall, B.M., and Levy, S.B. 2011. Food animals and antimicrobials: impacts on human 762 health. Clin. Microbiol. Rev. 24(4): 718-733. doi: 10.1128/CMR.00002-11. 
763 Marti, R., Tien, Y.-C., Murray, R., Scott, A., Sabourin, L., and Topp, E. 2014. Safely Coupling 764 Livestock and Crop Production Systems: How Rapidly Do Antibiotic Resistance Genes 765 Dissipate in Soil following a Commercial Application of Swine or Dairy Manure? Appl. Environ. Microbiol. 80(10):3258-3265. doi: 10.1128/AEM.00231-14.

767 Mathew, A.G., Beckmann, M.A., and Saxton, A.M. 2001. A comparison of antibiotic resistance in bacteria isolated from swine herds in which antibiotics were used or excluded. J. Swine Health Prod. 9(3):125-129.

Mauldin, P.D., Salgado, C.D., Hansen, I.S., Durup, D.T., and Bosso, J.A. 2010. Attributable hospital cost and length of stay associated with health care-associated infections caused by antibiotic-resistant gram-negative bacteria. Antimicrob. Agents Chemother. 54(1):

McEwen, S.A., and Fedorka-Cray, P.J. 2002. Antimicrobial use and resistance in animals. Clin. Infect. Dis. 34(Supplement 3):S93-S106. doi: 10.1086/340246.

Miranda, J., Vazquez, B., Fente, C., Barros-Velazquez, J., Cepeda, A., and Abuín, C.F. 2008. Antimicrobial resistance in Escherichia coli strains isolated from organic and conventional pork meat: a comparative survey. Eur. Food Res. Technol. 226(3):371-375. doi: 10.1007/s00217-006-0547-y.

Mølbak, K., Baggesen, D.L., Aarestrup, F.M., Ebbesen, J.M., Engberg, J., Frydendahl, K., Gerner-Smidt, P., Petersen, A.M., Wegener, H.C. 1999. An outbreak of multidrugresistant, quinolone-resistant Salmonella enterica serotype Typhimurium DT104. N. Engl. J. Med. 341: 1420-1425. 
784 Mølbak, L., Johnsen, K., Boye, M., Jensen, T.K., Johansen, M., Møller, K., and Leser, T.D.

785

786

787

788

789

790

791

792

793

794

795

796

797

798

799

800

801

802

803

804

805 2008. The microbiota of pigs influenced by diet texture and severity of Lawsonia intracellularis infection. Vet. Microbiol. 128(1):96-107.

doi:10.1016/j.vetmic.2007.09.012

Montagne, L., Arturo-Schaan, M., Le Floc'h, N., Guerra, L., and Le Gall, M. 2010. Effect of sanitary conditions and dietary fibre on the adaptation of gut microbiota after weaning. Livest. Sci. 133(1):113-116. doi:10.1016/j.livsci.2010.06.039.

Namkung, H., Li J. Gong, M., Yu, H., Cottrill, M., and de Lange, C. 2004. Impact of feeding blends of organic acids and herbal extracts on growth performance, gut microbiota and digestive function in newly weaned pigs. Can. J. Anim. Sci. 84(4):697-704.

Namkung, H., J. Gong, H. Yu, and C. F. M. de Lange. 2006. Effect of pharmacological intakes of zinc and copper on growth performance, circulating cytokines and gut microbiota of newly weaned piglets challenged with coliform lipopolysaccharides. Can. J. Anim. Sci. 86:511-522. doi: 10.4141/A05-075.

Niewold, T. 2007. The nonantibiotic anti-inflammatory effect of antimicrobial growth promoters, the real mode of action? A hypothesis. Poult. Sci. 86(4): 605-609. doi: $10.1093 / \mathrm{ps} / 86.4 .605$.

Nocker, A., Burr, M., and Camper, A.K. 2007. Genotypic microbial community profiling: a critical technical review. Microb. Ecol. 54(2):276-289. doi:10.1007/s00248-006-9199-5.

Pakpour, S., Jabaji, S., and Chénier, M.R. 2012. Frequency of antibiotic resistance in a swine facility 2.5 years after a ban on antibiotics. Microb. Ecol. 63(1):41-50. doi: 10.1007/s00248-011-9954-0. 
806 Park, S.J., Kim, J., Lee J.S., Rhee S.K., Kim, H. 2014. Characterization of the fecal microbiome 807 in different swine groups by high-throughput sequencing. Anaerobe. 28:157-62. doi: 10.1016/j.anaerobe.2014.06.002.

809 Pérez, V.G., Waguespack. A,M., Bidner, T.D., Southern, L.L., Fakler, T.M., Ward, T.L., 810 Steidinger, M., Pettigrew, J.E. 2011. Additivity of effects from dietary copper and zinc on

Public Health Agency of Canada. 2014. Canadian Integrated Program for Antimicrobial Resistance Surveillance (CIPARS) Annual Report 2010. http://publications.gc.ca/collections/collection_2014/aspc-phac/HP2-4-2010-eng.pdf. Accessed July 18, 2015.

Piddock, L.J. 2012. The crisis of no new antibiotics — what is the way forward? Lancet Infect Dis 12(3):249-253. doi: 10.1016/S1473-3099(11)70316-4.

Poole, T., Suchodolski, J., Callaway, T., Farrow, R., Loneragan, G., and Nisbet, D. 2013. The effect of chlortetracycline on faecal microbial populations in growing swine. J. Glob. Antimicrob. Resist. 1(3):171-174. doi:10.1016/j.jgar.2013.04.004.

Poretsky, R., Rodriguez-R, L.M., Luo, C., Tsementzi, D., Konstantinidis, K.T. 2014. Strengths and limitations of $16 \mathrm{~S}$ rRNA gene amplicon sequencing in revealing temporal microbial community dynamics. PLOS ONE. 9(4):e93827. doi: 10.1371/journal.pone.0093827.

Rettedal, E., Vilain, S., Lindblom, S., Lehnert, K., Scofield, C., George, S., Clay, S., Kaushik, R.S., Rosa, A.J., and Francis, D. 2009. Alteration of the ileal microbiota of weanling 
piglets by the growth-promoting antibiotic chlortetracycline. Appl. Environ. Microbiol.

830 75(17):5489-5495. doi: 10.1128/AEM.02220-08.

Roberts, R.R., Hota, B., Ahmad, I., Scott, R.D., Foster, S.D., Abbasi, F., Schabowski, S., Kampe, L.M., Ciavarella, G.G., and Supino, M. 2009. Hospital and societal costs of antimicrobial-resistant infections in a Chicago teaching hospital: implications for antibiotic stewardship. Clin. Infect. Dis. 49(8):1175-1184. doi: 10.1086/605630.

Rollo, S.N., Norby, B., Bartlett, P.C., Scott, H.M., Wilson, D.L., Fajt, V.R., Linz, J.E., Bunner, C.E., Kaneene, J.B., and Huber Jr, J.C. 2010. Prevalence and patterns of antimicrobial resistance in Campylobacter spp isolated from pigs reared under antimicrobial-free and conventional production methods in eight states in the Midwestern United States. J. Am. Vet. Med. Assoc. 236(2):201-210. doi:10.2460/javma.236.2.201.

Rosengren, L.B., Waldner, C.L., Reid-Smith, R.J., Dowling, P.M., and Harding, J.C. 2007. Associations between feed and water antimicrobial use in farrow-to-finish swine herds and antimicrobial resistance of fecal Escherichia coli from grow-finish pigs. Microb. Drug Resist. 13(4):261-270. doi:10.1089/mdr.2007.781.

Schokker, D., Zhang, J., Vastenhouw, S.A., Heilig, H.G., Smidt, H., Rebel, J.M., Smits, M.A. 2015. Long-lasting effects of early-life antibiotic treatment and routine animal handling on gut microbiota composition and immune system in pigs. PLOS ONE. 10(2):e0116523. doi:10.1371/journal.pone.0116523.

Silbergeld, E.K., Graham, J., and Price, L.B. 2008. Industrial food animal production, antimicrobial resistance, and human health. Annu. Rev. Public Health 29:151-169. doi: 10.1146/annurev.publhealth.29.020907.090904. 
850 Skinner, L., Levesque, C., Wey, D., Rudar, M., Zhu, J., Hooda, S., and de Lange, C. 2014. Impact of nursery feeding program on subsequent growth performance, carcass quality, meat quality, and physical and chemical body composition of growing-finishing pigs. J. Anim. Sci. 92(3):1044-1054. doi:10.2527/jas.2013-6743.

854 Slifierz, M.J., Friendship, R.M., Weese, J.S. 2015. Methicillin-resistant Staphylococcus aureus in commercial swine herds is associated with disinfectant and zinc usage. Appl. Environ. Microbiol. 81(8):2690-5. doi:10.1128/AEM.00036-15.

Sommer, F., and Bäckhed, F. 2013. The gut microbiota—masters of host development and physiology. Nat. Rev. Microbiol. 11(4):227-238. doi:10.1038/nrmicro2974.

Stanton, T.B., Humphrey, S.B., and Stoffregen, W.C. 2011. Chlortetracycline-resistant intestinal bacteria in organically raised and feral swine. Appl. Environ. Microbiol. 77(20):71677170. doi:10.1128/AEM.00688-11.

Stone, J.J., Clay, S.A., Zhu, Z., Wong, K.L., Porath, L.R., and Spellman, G.M. 2009. Effect of antimicrobial compounds tylosin and chlortetracycline during batch anaerobic swine manure digestion. Water Res. 43(18):4740-4750. doi:10.1016/j.watres.2009.08.005.

Sun, J., Li, L., Liu, B., Xia, J., Liao, X., and Liu, Y. 2014. Development of aminoglycoside and $\beta$-lactamase resistance among intestinal microbiota of swine treated with lincomycin, chlortetracycline, and amoxicillin. Front. Microbiol. 5:580. doi: 10.3389/fmicb.2014.00580.

Swann, M., Baxter, K., and Field, H. 1969. Report of the joint committee on the use of antibiotics in animal husbandry and veterinary medicine. Her Majesty's Stationary Office, London. 
872 Thomas, C.M., and Nielsen, K.M. 2005. Mechanisms of, and barriers to, horizontal gene transfer 873 between bacteria. Nat. Rev. Microbiol. 3(9):711-721. doi:10.1038/nrmicro1234.

874 Thomas, T., Gilbert, J., and Meyer, F. 2012. Metagenomics-a guide from sampling to data 875 analysis. Microb. Inform. Exp. 2(3). doi: 10.1186/2042-5783-2-3.

876 Thymann, T., Sørensen, K.U., Hedemann, M.S., Elnif, J., Jensen, B.B., Banga-Mboko, H., Leser, 877 T.D., and Sangild, P.T. 2007. Antimicrobial treatment reduces intestinal microflora and 878 improves protein digestive capacity without changes in villous structure in weanling pigs. Br. J. Nutr. 97(06): 1128-1137. doi:10.1017/S0007114507691910.

Turnbaugh, P.J., Ley, R.E., Hamady, M., Fraser-Liggett, C., Knight, R., and Gordon, J.I. 2007. The human microbiome project: exploring the microbial part of ourselves in a changing world. Nature 449(7164):804-810. doi:10.1038/nature06244.

United States Department of Agriculture. 2007. Swine Part II: Reference of swine health and health management practices in the United States. 2006. http://www.aphis.usda.gov/animal_health/nahms/swine/downloads/swine2006/Swine200 6_dr_PartII.pdf. Accessed July 18, 2015. 6_dr_PartIV.pdf. Accessed July 18, 2015.

891 United States Food and Drug Administration. 2011. 2011 Summary report on antimicrobials sold 892 of distributed for use in food-producing animals.

893 http://www.fda.gov/downloads/ForIndustry/UserFees/AnimalDrugUserFeeActADUFA/U 894 CM338170.pdf. Accessed July 18, 2015. 
895 United States Food and Drug Administration. 2013. Guidance for Industry. New Animal Drugs and New Animal Drug Combination Products Administered in or on Medicated Feed or Drinking Water of Food-Producing Animals: Recommendations for Drug Sponsors for Voluntarily Aligning Product Use Conditions with GFI \#209. http://www.fda.gov/downloads/animalveterinary/guidancecomplianceenforcement/guidan ceforindustry/ucm299624.pdf. Accessed July 18, 2015.

Vahjen, W., Pieper, R., Zentek, J. Bar-coded pyrosequencing of 16S rRNA gene amplicons reveals changes in ileal porcine bacterial communities due to high dietary zinc intake. Appl. Environ. Microbiol. 76(19):6689-91. doi:10.1128/AEM.03075-09.

Vahjen, W., Pieper, R., Zentek, J. 2011. Increased dietary zinc oxide changes the bacterial core

Viola, C., and DeVincent, S.J. 2006. Overview of issues pertaining to the manufacture, distribution, and use of antimicrobials in animals and other information relevant to animal antimicrobial use data collection in the United States. Prev. Vet. Med. 73(2): 111-

913 World Health Organization. 2012. The evolving threat of antimicrobial resistance: options for action. http://www.who.int/patientsafety/implementation/amr/publication/en. Accessed July 18, 2015. 
916 World Health Organization. 2011. Critically Important Antimicrobials for Human Medicine-3rd

917 Revision 2011. http://www.who.int/foodsafety/publications/antimicrobials-third/en/

$918 \quad$ Accessed July 18, 2015.

919 World Health Organization. 2014. Antimicrobial resistance: global report on surveillance.

920 http://www.who.int/drugresistance/documents/surveillancereport/en/. Accessed July 18, 2015.

922 Yazdankhah, S., Rudi, K., Bernhoft, A. 2014. Zinc and copper in animal feed - development

923 of resistance and co-resistance to antimicrobial agents in bacteria of animal

924 origin. Microb. Ecol. Health Dis. 25:25862. doi:10.3402/mehd.v25.25862.

925 Zhao W, Wang Y, Liu S, Huang J, Zhai Z, He C, Ding J, Wang J, Wang H, Fan W,

926 Zhao J, Meng H. 2015. The dynamic distribution of porcine microbiota across different

927 ages and gastrointestinal tract segments. PLOS ONE. 10(2):e0117441.

928 doi:10.1371/journal.pone.0117441.

929 Zhu YG, Johnson TA, Su JQ, Qiao M, Guo GX, Stedtfeld RD et al. (2013). Diverse and

930 abundant antibiotic resistance genes in Chinese swine farms. Proc. Natl. Acad. Sci. USA

$931 \quad$ 110:3435-3440. doi:10.1073/pnas.1222743110.

932 Zoetendal, E.G., Collier, C.T., Koike, S., Mackie, R.I., and Gaskins, H.R. 2004. Molecular 933 ecological analysis of the gastrointestinal microbiota: a review. J. Nutr. 134(2):465-472. 
Table 1. High throughput sequencing studies on the effect of antibiotics on the swine gut microbiota.

\begin{tabular}{|c|c|c|c|c|c|c|c|}
\hline Author & $\begin{array}{l}\text { Antibiotic and dosage } \\
\left(\mathrm{mg} \mathrm{kg}^{-1} \text { feed }\right)\end{array}$ & $\begin{array}{l}\text { 16S rRNA } \\
\text { hypervariable } \\
\text { region sequenced }\end{array}$ & $\begin{array}{l}\text { Number of pigs } \\
\text { used per } \\
\text { treatment group }\end{array}$ & $\begin{array}{l}\text { Duration of } \\
\text { study (age of } \\
\text { pigs in } \\
\text { weeks) }\end{array}$ & $\begin{array}{l}\text { Sequencing } \\
\text { platform }\end{array}$ & $\begin{array}{l}\text { Sample } \\
\text { type }\end{array}$ & Notable findings \\
\hline $\begin{array}{l}\text { Allen et al. } \\
2011\end{array}$ & $\begin{array}{l}\text { Carbadox: 10; carbadox: } \\
\text { 50; ASP250: } \\
\text { (chlortetracycline: } \\
\text { 100,sulfamethazine: } 100, \\
\text { penicillin:50) }\end{array}$ & $\begin{array}{l}\text { Whole genome } \\
\text { sequencing of } \\
\text { virome; } 16 \mathrm{~S} \\
\text { rRNA V1-V3 }\end{array}$ & $\begin{array}{l}\text { Six (pooled for } \\
\text { WGS) }\end{array}$ & 3 to 7 & 454 GS-FLX & Feces & $\begin{array}{l}\text { ASP250 pigs: Shift in phage and } \\
\text { bacterial communities; } \uparrow \\
\text { Escherichia; } \uparrow \text { integrase genes in } \\
\text { ASP } 250+\text { carbadox pigs }\end{array}$ \\
\hline $\begin{array}{l}\text { Holman and } \\
\text { Chénier } 2014\end{array}$ & $\begin{array}{l}\text { Tylosin: 11, 22, } 44 \\
\text { Chlortetracycline: } 5.5\end{array}$ & V4 & Six & 3 to 19 & Illumina MiSeq & Feces & $\begin{array}{l}\text { Tylosin pigs: Shift in bacterial } \\
\text { community structure; } \uparrow \\
\text { Coprococcus }(3 \text { to } 9 \mathrm{wk}) ; \downarrow \\
\text { Fibrobacteres, }(3 \mathrm{wk}) ; \uparrow \\
\text { Streptococcus }(6 \mathrm{wk}) ; \downarrow \\
\text { Bacteroidetes }(9 \mathrm{wk}) ; \downarrow \\
\text { Succinivibrio }(9 \mathrm{wk}) \\
\text { Chlortetracycline pigs: } \downarrow \text { Bacteria } \\
(3 \mathrm{wk}) ; \downarrow \text { Lactobacillus }(6 \mathrm{wk}) ; \downarrow \\
\text { Firmicutes }(16 \mathrm{wk})\end{array}$ \\
\hline Kim et al. 2012 & Tylosin: 40 & V3 & $\begin{array}{l}\text { Two farms }-10 \\
\text { pigs per } \\
\text { treatment at } \\
\text { each farm } \\
\text { (pooled) }\end{array}$ & 10 to 22 & 454 GS-FLX & Feces & $\begin{array}{l}\text { Tylosin pigs: } \downarrow \text { Prevotella, } \\
\text { Megasphaera, Blautia, Sarcina; } \uparrow \\
\text { Lactobacillus, Sporacetigenium } \\
\text { No effect on alpha or beta diversity }\end{array}$ \\
\hline $\begin{array}{l}\text { Looft et al. } \\
2012\end{array}$ & ASP250 & $\begin{array}{l}\text { Whole genome } \\
\text { sequencing; 16S } \\
\text { rRNA V1-V3 }\end{array}$ & Three & 18 to 21 & 454 GS-FLX & Feces & $\begin{array}{l}\text { ASP250 pigs: } \downarrow \text { Bacteroidetes, } \\
\text { Anaerobacter, Barnesiella, } \\
\text { Papillibacter, } \\
\text { Sporacetigenium, Sarcina; } \\
\uparrow \text { Deinococcus-Thermus, } \\
\text { Proteobacteria, Succinivibrio, } \\
\text { Ruminococcus, E. coli; } \uparrow \text { diversity } \\
\text { and abundance of antibiotic } \\
\text { resistance genes }\end{array}$ \\
\hline $\begin{array}{l}\text { Looft et al. } \\
2014 \mathrm{a}\end{array}$ & ASP250 & $\begin{array}{l}\text { Whole genome } \\
\text { sequencing; 16S } \\
\text { rRNA V1-V3 }\end{array}$ & Six & 12 to 14 & 454 GS-FLX & $\begin{array}{l}\text { Ileum, } \\
\text { cecum, } \\
\text { colon: } \\
\text { tissue and }\end{array}$ & $\begin{array}{l}\text { ASP250 pigs: } \uparrow \text { Tenericutes in } \\
\text { cecum, } \uparrow \text { Escherichia in cecum and } \\
\text { colon; } \uparrow \text { Paraprevotella, } \\
\text { Anaeroplasma in the cecum; } \downarrow\end{array}$ \\
\hline
\end{tabular}


Looft et al. Carbadox: 50

$2014 b$

Poole et al

2013

Sun et al. 2014

Chlortetracycline: 50

Mixture of: lincomycin

hydrochloride: 500 ;

chlortetracycline:100;

amoxicillin 500
V1-V3

V1-V3

V3-V5

V3-V5
Six

Two

24 pregnant

sows (nine

samples pooled

at each time

point)
6 to 9

(treatment)

10 to 15

(withdrawal

period)

4 to 11

7 to 11

(treatment)

Treatment

duration: 12

days lumen

454 GS-FLX Feces
454 GS-FLX Feces

454 GS-FLX

Feces
Treponema in cecum and colon,

Carbadox pigs: $\uparrow$ at days 1-4

Bacteroidetes, Prevotella,

Roseburia, Faecalibacterium,

Asteroleplasma; $\downarrow$ at days 1-4

Lactobacillus; $\downarrow$ alpha-diversity in

1-4 day samples but not 7 days+;

shifts in beta-diversity in 1-4 day samples but not 7 days +

No differences in alpha or betadiversity, nor at the taxa-level

Following treatment: $\downarrow$ Proteobacteria (3 to 12 days);

$\downarrow$ Escherichia/Shigella;

Streptococcus (days 3 and 6); $\uparrow$

Bacteroidetes, Spirochaetes,

Euryarchaeota, Actinobacteria (days 3 and 6);

$\uparrow$ aminoglycoside, lincomycin, macrolides, and tetracycline

resistance genes 
Table 1. High throughput sequencing studies on the effect of antibiotics on the swine gut microbiota.

\begin{tabular}{|c|c|c|c|c|c|c|c|}
\hline Author & $\begin{array}{l}\text { Antibiotic and dosage } \\
\left(\mathrm{mg} \mathrm{kg}^{-1} \text { feed }\right)\end{array}$ & $\begin{array}{l}\text { 16S rRNA } \\
\text { hypervariable } \\
\text { region sequenced }\end{array}$ & $\begin{array}{l}\text { Number of pigs } \\
\text { used per } \\
\text { treatment group }\end{array}$ & $\begin{array}{l}\text { Duration of } \\
\text { study (age of } \\
\text { pigs in } \\
\text { weeks) }\end{array}$ & $\begin{array}{l}\text { Sequencing } \\
\text { platform }\end{array}$ & $\begin{array}{l}\text { Sample } \\
\text { type }\end{array}$ & Notable findings \\
\hline $\begin{array}{l}\text { Allen et al. } \\
2011\end{array}$ & $\begin{array}{l}\text { Carbadox: 10; carbadox: } \\
\text { 50; ASP250: } \\
\text { (chlortetracycline: } \\
\text { 100,sulfamethazine: } 100, \\
\text { penicillin:50) }\end{array}$ & $\begin{array}{l}\text { Whole genome } \\
\text { sequencing of } \\
\text { virome; } 16 \mathrm{~S} \\
\text { rRNA V1-V3 }\end{array}$ & $\begin{array}{l}\text { Six (pooled for } \\
\text { WGS) }\end{array}$ & 3 to 7 & 454 GS-FLX & Feces & $\begin{array}{l}\text { ASP250 pigs: Shift in phage and } \\
\text { bacterial communities; } \uparrow \\
\text { Escherichia; } \uparrow \text { integrase genes in } \\
\text { ASP } 250+\text { carbadox pigs }\end{array}$ \\
\hline $\begin{array}{l}\text { Holman and } \\
\text { Chénier } 2014\end{array}$ & $\begin{array}{l}\text { Tylosin: } 11,22,44 \\
\text { Chlortetracycline: } 5.5\end{array}$ & V4 & Six & 3 to 19 & Illumina MiSeq & Feces & $\begin{array}{l}\text { Tylosin pigs: Shift in bacterial } \\
\text { community structure; } \uparrow \\
\text { Coprococcus }(3 \text { to } 9 \mathrm{wk}) ; \downarrow \\
\text { Fibrobacteres, }(3 \mathrm{wk}) ; \uparrow \\
\text { Streptococcus }(6 \mathrm{wk}) ; \downarrow \\
\text { Bacteroidetes }(9 \mathrm{wk}) ; \downarrow \\
\text { Succinivibrio }(9 \mathrm{wk}) \\
\text { Chlortetracycline pigs: } \downarrow \text { Bacteria } \\
(3 \mathrm{wk}) ; \downarrow \text { Lactobacillus }(6 \mathrm{wk}) ; \downarrow \\
\text { Firmicutes }(16 \mathrm{wk})\end{array}$ \\
\hline Kim et al. 2012 & Tylosin: 40 & V3 & $\begin{array}{l}\text { Two farms }-10 \\
\text { pigs per } \\
\text { treatment at } \\
\text { each farm } \\
\text { (pooled) }\end{array}$ & 10 to 22 & 454 GS-FLX & Feces & $\begin{array}{l}\text { Tylosin pigs: } \downarrow \text { Prevotella, } \\
\text { Megasphaera, Blautia, Sarcina; } \uparrow \\
\text { Lactobacillus, Sporacetigenium } \\
\text { No effect on alpha or beta diversity }\end{array}$ \\
\hline $\begin{array}{l}\text { Looft et al. } \\
2012\end{array}$ & ASP250 & $\begin{array}{l}\text { Whole genome } \\
\text { sequencing; 16S } \\
\text { rRNA V1-V3 }\end{array}$ & Three & 18 to 21 & 454 GS-FLX & Feces & $\begin{array}{l}\text { ASP250 pigs: } \downarrow \text { Bacteroidetes, } \\
\text { Anaerobacter, Barnesiella, } \\
\text { Papillibacter, } \\
\text { Sporacetigenium, Sarcina; } \\
\uparrow \text { Deinococcus-Thermus, } \\
\text { Proteobacteria, Succinivibrio, } \\
\text { Ruminococcus, E. coli; } \uparrow \text { diversity } \\
\text { and abundance of antibiotic } \\
\text { resistance genes }\end{array}$ \\
\hline $\begin{array}{l}\text { Looft et al. } \\
2014 \mathrm{a}\end{array}$ & ASP250 & $\begin{array}{l}\text { Whole genome } \\
\text { sequencing; 16S } \\
\text { rRNA V1-V3 }\end{array}$ & Six & 12 to 14 & 454 GS-FLX & $\begin{array}{l}\text { Ileum, } \\
\text { cecum, } \\
\text { colon: } \\
\text { tissue and }\end{array}$ & $\begin{array}{l}\text { ASP250 pigs: } \uparrow \text { Tenericutes in } \\
\text { cecum, } \uparrow \text { Escherichia in cecum and } \\
\text { colon; } \uparrow \text { Paraprevotella, } \\
\text { Anaeroplasma in the cecum; } \downarrow\end{array}$ \\
\hline
\end{tabular}


Looft et al. Carbadox: 50

$2014 b$

Poole et al

2013

Sun et al. 2014

Chlortetracycline: 50

Mixture of: lincomycin

hydrochloride: 500 ;

chlortetracycline:100;

amoxicillin 500
V1-V3

V1-V3

V3-V5

V3-V5
Six

Two

24 pregnant

sows (nine

samples pooled

at each time

point)
6 to 9

(treatment)

10 to 15

(withdrawal

period)

4 to 11

7 to 11

(treatment)

Treatment

duration: 12

days lumen

454 GS-FLX Feces

454 GS-FLX Feces

454 GS-FLX
Treponema in cecum and colon,

Carbadox pigs: $\uparrow$ at days 1-4

Bacteroidetes, Prevotella,

Roseburia, Faecalibacterium,

Asteroleplasma; $\downarrow$ at days 1-4

Lactobacillus; $\downarrow$ alpha-diversity in

1-4 day samples but not 7 days+;

shifts in beta-diversity in 1-4 day samples but not 7 days +

No differences in alpha or betadiversity, nor at the taxa-level

Following treatment: $\downarrow$ Proteobacteria (3 to 12 days);

$\downarrow$ Escherichia/Shigella;

Streptococcus (days 3 and 6); $\uparrow$

Bacteroidetes, Spirochaetes,

Euryarchaeota, Actinobacteria (days 3 and 6);

$\uparrow$ aminoglycoside, lincomycin, macrolides, and tetracycline

resistance genes 